\title{
POPULAC̣ÃO NEGRA E CIVILIZAC̣ÃO: \\ uma análise a partir do estabelecimento da obrigatoriedade escolar em Minas Gerais (1830-1850)
}

Marcus Vinicios Fonseca*

RESUMO: Este artigo analisa o processo de estabelecimento da obrigatoriedade escolar como elemento de mediação entre o perfil racial da população e a ideia de civilização que orientou o processo de construção da educação em Minas Gerais. No século XIX, havia predomínio absoluto dos negros na população mineira e isso pode ser tomado como referência para que a ideia de obrigatoriedade escolar assumisse a condição de instrumento de normatização e controle de certos aspectos deste segmento populacional. Para tratar dessas questões, utilizamos como referência a documentação censitária que, nos anos de 1830, processou a contagem da população de Minas Gerais, Relatórios de Presidente de Província, memórias e relatos de viagem de indivíduos que travaram contanto com a sociedade mineira na primeira metade do século XIX.

Palavra-chave: Negros; Escolarização; História da educação.

BLACK PEOPLE POPULATION AND CIVILIZATION: ANALYSIS SINCE THE ESTABLISHMENT OF SCHOOL OBLIGATION IN MINAS GERAIS STATE/ BRAZIL (1830-1850)

ABSTRACT: This article analyzes the process of the school obligation establishment as an element of mediation between the racial profile of the population and the idea of civilization that oriented the process of educational construction in Minas Gerais State. In the nineteenth century, it was an expressive predominance of the black population in Minas Gerais. This fact can be taken as a reference for the idea that school obligation had become a condition to guide the regulation and to control certain aspects of that part of the population. In order to carry this analysis through, we used as reference a census documentation that, in 1831, counted the population of all districts of Minas Gerais, Reports of Provincial Presidents, narration of voyage and memories of the people that was in contact with the population of Minas Gerais in the nineteenth century. Keywords: Black people; Schooling; Educational History.

* Doutor em Educação pela Universidade de São Paulo (USP), Mestre em educação pela Universidade Federal de Minas Gerais (UFMG), atualmente em processo de pósdoutoramento na Universidade Federal de Minas Gerais (UFMG) como bolsista da FAPEMIG. E-mail: mvfonseca@bol.com.br 


\section{INTRODUÇÃO}

Um dos aspectos mais interessantes em relação ao processo de escolarização em Minas Gerais encontra-se no fato de que, em 1835, foi estabelecida a obrigatoriedade da instrução elementar. Essa iniciativa foi além do que havia sido estabelecido pelo governo do Império, que determinara apenas a gratuidade da instrução. Em 1835, a lei mineira de n. 13 se sobrepôs à Constituição do Império e estabeleceu que, em Minas Gerais, a instrução elementar era gratuita e obrigatória.

Essa lei é tida como um marco para o entendimento do estabelecimento do processo de escolarização em Minas Gerais, e o que tem sido destacado pela historiografia é o seu caráter simbólico, pois a obrigatoriedade da instrução era algo praticamente impossível de ser cumprido na primeira metade do século XIX. Tendo como referência a dimensão simbólica, as análises históricas procuram demonstrar como essa lei representa a manifestação de um novo estatuto para a infância, que passa a ser concebida como um período da vida que deveria ser vivenciado dentro do espaço escolar. De outro lado, as análises também têm colocado em relevo o papel que escola passa a ter na construção de um povo civilizado e em sintonia com padrão de organização da sociedade moderna.

Este artigo tem como ponto de partida as questões destacadas pelas análises que vêm sendo construídas pela historiografia, mas procura estabelecer uma relação entre essa legislação e o perfil da população de Minas Gerais, cuja principal característica era o predomínio do grupo racial representado pelos negros. O que tentaremos demonstrar é que Minas Gerais era a província brasileira com maior número de escravos e negros livres em meio à população e é provável que isso tenha sido considerado por aqueles que estabeleceram que a educação tinha importante papel a cumprir no processo de construção de um povo civilizado.

Para tratar dessas questões, utilizaremos como referência a lei que estabeleceu a obrigatoriedade da instrução elementar e as informações sobre educação que aparecem nos relatórios de Presidente de Província durante os anos de 1830 e 1840. Utilizaremos também a documentação censitária que se refere às tentativas de contagem da população ocorridas em Minas no início da década de 1830; documentos 
que fazem referência à educação, como memórias de indivíduos que vivenciaram o processo de escolarização durante a primeira metade do século XIX; e relatos de viajantes que, durante esse período, passaram por Minas Gerais.

\section{O CARÁTER SIMBÓLICO DA OBRIGATORIEDADE ESCOLAR EM MINAS GERAIS}

As discussões encaminhadas durante os primeiros anos de funcionamento do governo provincial em Minas Gerais revelam que havia, por parte das autoridades públicas, certa preocupação relacionada à educação da população. Isso pode ser constatado nos Relatórios de Presidente de Província, nos quais as questões sobre educação eram apresentadas por meio de iniciativas tomadas no campo da legislação e dos investimentos dirigidos à instrução. Mas, de maneira geral, os documentos que se referem às atividades empreendidas pelo governo de Minas Gerais, em suas primeiras décadas de funcionamento, revelam que a instrução era uma questão que estava em pauta nos debates sobre a organização da província.

A recorrência com que as questões relativas à instrução eram apresentadas é uma representação de seu papel como instrumento na formação de um povo ordeiro e civilizado. Segundo Faria Filho e Resende (2001, p. 113), a análise dos discursos e das ações produzidas a partir do poder legislativo e do executivo revelam essa dimensão: "a ação política está nos discursos e, sem dúvida, nos temas dignos dos mesmos. Produzilos como dignos de notoriedade de atenção do executivo e do legislativo provinciais e, quase sempre, de toda a população mineira, explicita uma intencionalidade política direcionada e articulada pela idéia de educação como um ato e uma condição de civilidade".

Embora seja possível detectar toda essa mobilização em torno da instrução, isso deve ser tomado como algo simbólico, pois há contradição entre a realidade da província e as propostas que emanavam do poder público, principalmente por meio da intensa atividade legislativa que se desenvolveu durante todo período imperial. Um dos elementos que revelam essa dimensão simbólica da instrução é a lei que foi aprovada em 1835, de n. 13, que definia as principais características do projeto 
educcional a ser implantado em Minas e que, segundo Faria Filho e Gonçalves (2004), se estabeleceu como parâmetro para as ações implementadas em momentos posteriores.

A Lei n. 13 era composta por trinta artigos que definiam aspectos como a divisão da instrução primária em dois graus, o público ao qual era dirigida (os meninos de 8 a 14 anos) e incentivos para a educação do sexo feminino. Trouxe várias questões relativas ao processo de formação dos professores, como a criação de uma escola normal, o investimento no aprimoramento dos métodos de ensino e as condições para inserção e atuação na carreira do magistério. E, ainda, o processo de organização da instrução na província, que deveria ter um delegado em cada Comarca e este teria como função a fiscalização das escolas.

Dentro do conjunto de normas estabelecidas para a instrução pela Lei n. 13, o que mais chama a atenção é a sua sobreposição à Constituição do Império ao estabelecer a gratuidade e a obrigatoriedade escolar: "percebe-se, assim, que, apesar de a Constituição do Império determinar, em seu artigo 179, apenas a gratuidade da instrução primária, e não a sua obrigatoriedade, que os legisladores mineiros foram além e procuraram criar mecanismos para que se efetivasse de fato a matrícula e a freqüência das crianças na escola (FARIA FILHO; GONÇALVES, 2004, p. 161)".

Minas Gerais foi uma das primeiras províncias brasileiras a estabelecer a obrigatoriedade escolar e isso pode ser considerado uma manifestação da importância atribuída à educação do povo, pois, na verdade, tratava-se de algo que estava fora do alcance da ação governamental, que não tinha como disponibilizar vagas para o atendimento do que foi estabelecido pela Lei n. 13. Estava também distante da grande maioria da população que, além de não contar com o que poderíamos chamar de uma tradição de escolarização, estava longe de dispor dos recursos necessários para o cumprimento dessa exigência.

As dificuldades em relação à efetivação dessa disposição legal e seu significado simbólico podem ser evidenciados quando consideramos a expansão do número de alunos matriculados logo após a aprovação da lei e que se encontram registrados nos relatórios de Presidente de Província, entre os anos de 1837 e 1850.

Os registros contidos nos relatórios de Presidente de Província apresentam, com frequência, advertências quanto à dificuldade de se 
coletar dados relativos às matrículas nas escolas mineiras, portanto não oferecerem um retrato fiel das matrículas, mas apresentam dados que podem ser tomados como indícios do nível de difusão da instrução na população e as dificuldades de cumprimento da exigência quanto à obrigatoriedade.

Analisamos, nos relatórios, o registro do número de alunos das escolas públicas de primeiro e segundo graus do sexo masculino, entre 1837 e 1849, e percebemos que houve pequeno crescimento do número de alunos nos anos imediatamente posteriores à aprovação da lei que estabeleceu a obrigatoriedade da instrução, mas esse crescimento não se sustentou sequer por uma década, como pode ser visto no gráfico a seguir:

Gráfico 1: Número de alunos matriculados nas escolas da província Minas Gerais (1837-1850)

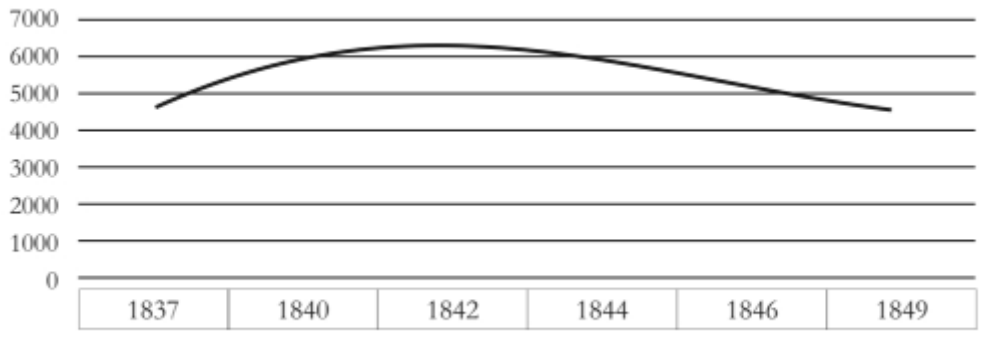

Fonte: Relatório de Presidente de Província

O relatório de 1837 registrou 4.587 alunos nas escolas públicas de instrução elementar. Esse número atingiu o maior índice em 1842, com 6.308 alunos, e caiu para 5.810 alunos, em 1844; logo em seguida, caiu para 5.201 alunos, em 1846, chegando a 4.527 alunos, em 1849. Ou seja, quando consideramos esse intervalo pouco superior a uma década, constatamos que, após a aprovação da lei que definiu a obrigatoriedade escolar, em 1835, houve pequeno crescimento do número de alunos e, na década seguinte, houve redução que, em 1849, deixou o número de alunos inferior ao que foi registrado em $1837^{1}$.

Os registros contidos nos relatórios de Presidente de Província são imprecisos e apresentam apenas dados sobre as aulas públicas. Segundo o relatório de 1851, o número de aulas particulares era no 
mínimo equivalente às públicas, pois os mecanismos de controle sobre essas aulas eram muitos frágeis e isso impedia qualquer tipo de estimativa mais confiável sobre o número de aulas particulares existentes. Portanto, é preciso levar em conta que havia certa equivalência entre as aulas públicas e as particulares, indicando que o número de alunos era superior ao que fora registrado nos relatórios de Presidente de Província.

No entanto, é preciso considerar que os relatórios de Presidente de Província apontam para o fato de que não houve crescimento expressivo no número de alunos para período posterior à aprovação da lei, em 1835. Dessa forma, torna-se evidente que a questão da gratuidade e da obrigatoriedade da instrução elementar foi apenas uma intenção, pois a aprovação da lei não foi acompanhada pelo aumento das matrículas nas escolas mineiras.

Isso pode ser considerado uma manifestação do caráter simbólico atribuído à educação em meio aos discursos que pretendiam demarcar a importância de civilizar o povo. Isso se torna ainda mais evidente quando avaliamos o nível de cobertura e atendimento da instrução elementar para a população em idade escolar que também revelam a distância entre a realidade da província em relação à necessidade do cumprimento da obrigatoriedade escolar.

\section{NÍVEL DE ATENDIMENTO À POPULAC̣ÃO EM IDADE ESCOLAR NO INÍCIO DOS ANOS DE 1830}

Não é possível ter uma avaliação precisa da população em idade escolar durante a primeira metade do século XIX, pois não havia, nesse período, a preocupação de estabelecer cálculos sobre esse segmento, o que, por sua vez, torna praticamente impossível encontrar, na documentação do período, qualquer estimativa sobre esse grupo. Porém, se não havia preocupação em estabelecer recortes específicos sobre os grupos passíveis de serem submetidos aos processos de escolarização, isso não quer dizer que o governo provincial não manifestasse o desejo de conhecer aspectos mais gerais da população mineira. Durante os anos de 1830, o governo demonstrou interesse em conhecer características da população e, para isso, viabilizou censos provinciais, que foram realizados durante os anos de 1830. A documentação relativa a esses censos 
encontra-se no Arquivo Público Mineiro e está organizada por listas nominais de habitantes.

As listas nominais de habitantes foram construídas a partir dos distritos e registraram cada um dos domicílios e seus respectivos moradores. Elas registraram o nome de cada habitante do domicílio, qualidade (raça/cor), condição (livre ou escravo), idade, estado civil e ocupação. Não há nenhum indicativo de que as crianças que estavam na escola deviam ser registradas, mas algumas listas fizeram esse registro no campo que assinalava a ocupação. $\mathrm{O}$ número de listas que registram crianças na escola não é muito elevado e é totalmente irregular, mas possibilita o cálculo da população em idade escolar e do nível de atendimento em relação à instrução elementar para alguns distritos.

Encontramos listas que não registram crianças na escola, outras que assinalam mais de cem nessa condição e ainda outras que registram apenas duas ou três crianças como alunos. Para contornar as distorções em torno dessa irregularidade no tratamento das crianças que estavam na escola, utilizamos como referência apenas as listas nominais que registraram mais de 24 crianças em processo de escolarização, que, segundo a legislação da época, era o número mínimo de alunos utilizado como referência para justificar a existência de uma aula pública em distrito. Para tornar ainda mais controlados os procedimentos de análise, utilizamos apenas as listas que se referem ao início dos anos de 1830 e que se referiam aos distritos localizados na região central da província, ou seja, nas comarcas de Sabará e Ouro Preto.

A região central foi o núcleo a partir do qual se deu o processo de povoamento de Minas Gerais e é a região que se desenvolveu tendo como referência a atividade mineradora. Como consequência desse processo, encontramos, nessa região, no século XIX, uma série de vilas e distritos com relativo desenvolvimento urbano e demográfico, sendo, portanto, um dos pontos em que havia maior concentração de escolas.

Esses critérios determinaram a escolha dos seguintes distritos da região central da província de Minas: São Bartolomeu, Itaverava, Santa Luzia, Caeté, Cachoeira do Campo, Bom Fim, Passagem, Redondo, Matosinho, Catas Altas.

Antes de estabelecer o nível de cobertura da instrução elementar em relação à população desses distritos, de modo que possamos avaliar a distância entre a obrigatoriedade escolar e o nível de cobertura em cada 
um deles, é necessário definir qual o grupo que representava aquilo que, a partir de um vocabulário contemporâneo, chamamos de população em idade escolar.

A lei que estabeleceu a obrigatoriedade escolar também se preocupou em normatizar e definir o público ao qual a escola estava destinada, pois a faixa etária daqueles que estavam nas escolas era muito variada e se encontrava longe de qualquer padronização. As listas nominais revelam que havia indivíduos de 4 a 20 anos frequentando as escolas de primeiras letras. Os registros contidos nas listas demonstram essa heterogeneidade e indicam a existência de diferentes grupos de idade em meio àqueles que foram definidos como na escola. Diante dessa heterogeneidade, a Lei n. 13 procurou definir com precisão e clareza o grupo que de fato deveria frequentar a escola elementar:

Art. 12. . Os Pais de Família são obrigados a dar a seus filhos a instrução primária do 1o. grau ou nas Escolas Públicas, ou particulares, ou em suas próprias casas, e não os poderão tirar delas, em quanto não souberem as matérias próprias do mesmo grau (...) Art. 13․ A obrigação imposta no artigo precedente aos Pais de Família começa aos oito anos de idade dos meninos, mas se estende aos que atualmente tiverem quatorze anos de idade. (LIVRO DAS LEIS MINEIRAS, p. 29)

A lei definiu como obrigatória a instrução primária e definiu a idade apropriada para escolarização como aquela que compreendia a faixa etária dos 8 aos 14 anos, mas apenas para o sexo masculino e para aqueles que eram de condição livre.

Quando analisamos o público registrado como na escola nas listas nominais do período que se refere aos anos iniciais da década de 1830, constatamos que a legislação de 1835 acompanhou aquilo que, de certa forma, era uma prática da população mineira. A maioria das crianças registradas como na escola estavam na idade de 8 a 14 anos, que foi a faixa etária definida pela legislação. Ao longo do século XIX, houve uma variação da faixa etária definida como adequada à escolarização e isso se reflete na legislação educacional que foi sendo construída durante o século XIX:

$\mathrm{Na}$ legislação educacional as idades foram dispostas para fixar o grupamento etário de crianças cujos pais ou responsáveis eram obrigados a dar instrução elementar e em especial a freqüência às aulas públicas. A lei de n. 13 de 1835 
prescreve a obrigatoriedade para meninos entre 08 e 14 anos, a lei 1769, regulamento 62 de 1872 indica meninos entre 08 a 15 anos e a lei 2892, regulamento 100 de 1883, obrigatoriedade para meninos entre 07 a 12 anos e meninas entre 06 e 11 anos (...) outras normas foram se organizando, tendo em vista talvez, o movimento da população em direção a escola. Isso pode ser observado na lei 1064, regulamento 49 de 1860 que dispõem sobre a proibição de matrícula nas aulas públicas de meninos menores de 05 anos e a lei 2476, regulamento 84 de 1879 que proíbe a matrícula para menores de 05 e maiores de 14 anos (VEIGA, 2006, p. 10).

Embora houvesse variações, a faixa etária entre 8 e 14 anos se estabeleceu como o período que foi sendo definido como apropriado para a escolarização, pois, tendo como referência as informações apresentadas por Veiga (2006), pode-se dizer que somente na legislação de 1883, que restringiu a idade escolar para o período entre 7 e 12 anos, houve mudança em que o referido intervalo não estava contido na definição legal.

Considerando o intervalo de idade e as restrições estabelecidas pela Lei n. 13 em relação ao sexo feminino e aos escravos, utilizamos as listas nominais para calcular a população em idade escolar nos dez distritos mineiros que selecionamos e o nível de atendimento em relação a essa população, ou seja, as crianças livres dessa faixa etária que foram registradas como na escola. Para efetuar o cálculo da população em idade escolar utilizamos os registros de todas as crianças livres, do sexo masculino, entre 8 e 14 anos. Em seguida, calculamos o nível de atendimento a essa população pelo registro de todas aquelas que, dentro dessa faixa etária, foram listadas como na escola. As crianças que estavam na escola, mas que não se encontravam na faixa etária definida pela Lei n. 13, não foram consideradas no cálculo. Tomamos o mesmo procedimento em relação às meninas e aos escravos, pois, como dissemos, a obrigatoriedade foi definida apenas para a população livre e do sexo masculino.

Antes de apresentar os dados relativos às crianças em idade escolar, apresentaremos os dados sobre a população de cada um dos distritos para que possam ser confrontados com aqueles que se referem aos aspectos mais gerais de cada uma das localidades. 
Gráfico 2: População registrada nas listas nominais por número de indivíduos

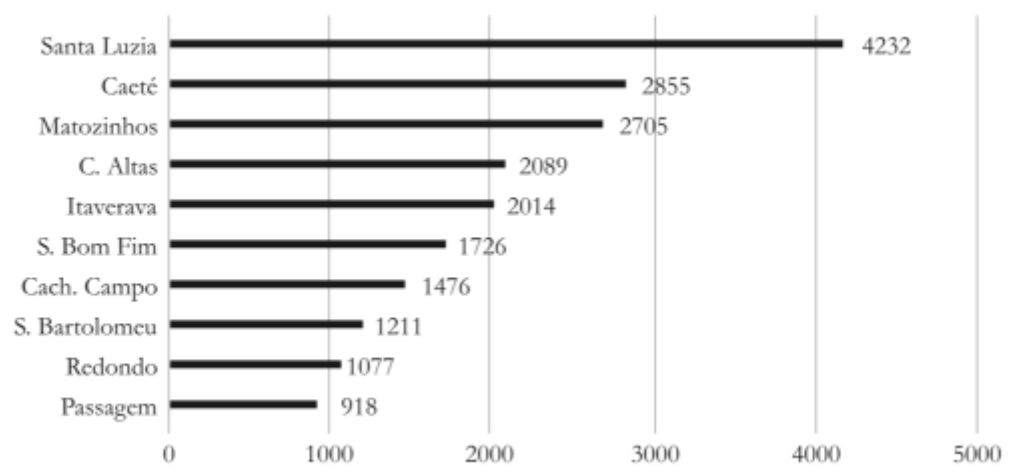

Fonte: Arquivo Público Mineiro - listas nominal de habitantes

Os dados relativos à população foram organizados em ordem decrescente e apontam para uma divisão dos distritos em três grupos: os que tinham população inferior a 2.000 habitantes (que eram cinco distritos: Passagem, Redondo, São Bartolomeu, Cachoeira do Campo, Bom Fim); os de população entre 2.000 e 3.000 habitantes (quatro distritos: Itaverava, Catas Altas, Matozinhos, Caeté), e o que possuía mais de 3.000 habitantes (Santa Luzia).

Gráfico 3: População em idade escolar de acordo a Lei n. 13 - (\%)

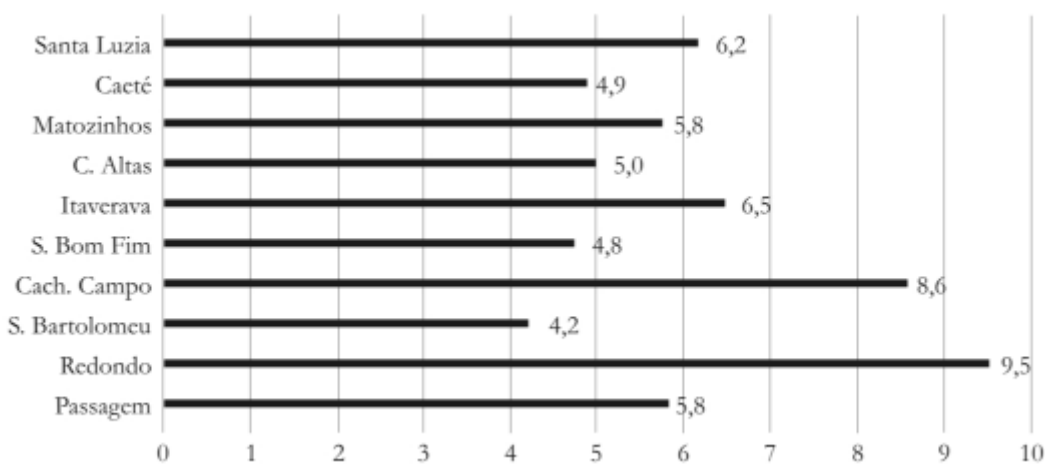

Fonte: Arquivo Público Mineiro - listas nominais de habitantes

O gráfico indica que o segmento definido como em idade escolar pela Lei n. 13 se distribuía de forma relativamente semelhante 
entre os diferentes distritos e isso revela certa regularidade estatística, pois não há discrepância e os índices estão próximos dos $6 \%$ da população total de cada distrito. Encontramos um índice relativamente superior no distrito de Redondo (9,5\%) e isso pode ser justificado em função de a lista nominal apresentar o Colégio Bom Jesus do Matozinhos como domicílio. Esse colégio aparece na lista como domicílio e grande parte dos alunos que foram registrados eram de outros distritos ou de outras províncias, e lá viviam em regime de internato. Há o registro do total 110 estudantes e bom número deles estava na idade estabelecida como escolar, portanto parte dos alunos do colégio era originária de outras regiões e foi listada como moradores do distrito de Redondo, o que representou acréscimo significativo para sua população, que está entre os distritos que têm os menores contingentes populacionais da amostra que recortamos, apenas 1.077 indivíduos ${ }^{2}$. Portanto, a população de Redondo era tão diminuta que o contingente de alunos do colégio representava fator de pressão que influenciava na composição demográfica dali, o que, por sua vez, elevava o índice da população em idade escolar, deixando-a em um nível relativamente superior ao dos outros distritos.

As listas nominais que utilizamos foram escolhidas com base no critério que considerou o número mínimo de 24 alunos registrados nas escolas de primeiras letras. Portanto, em todas as listas há certo nível de atendimento à população em idade escolar, mas esse atendimento ocorria a partir de um padrão irregular que atingia níveis elevados em alguns distritos e muito baixo em outros:

Gráfico 4: Nível de atendimento à população em idade escolar a partir da definição da Lei n. 13 - (\%)

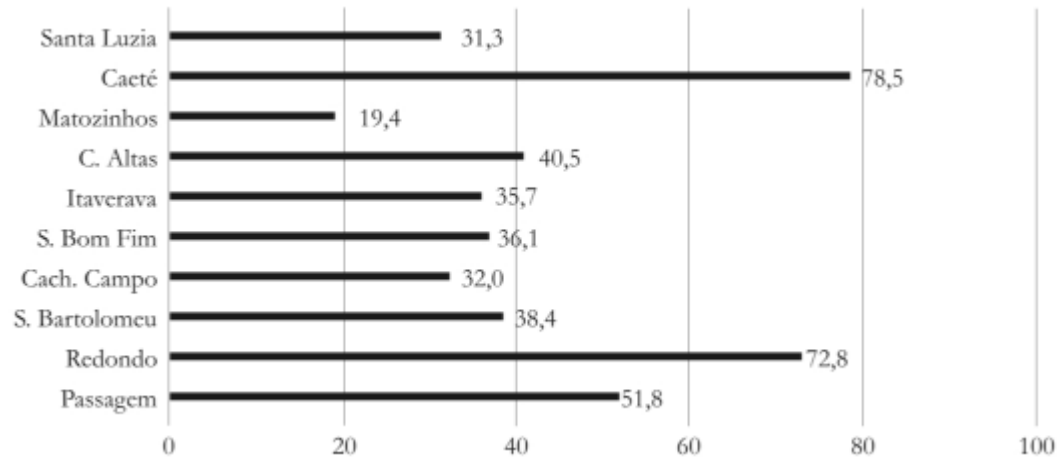

Fonte: Arquivo Público Mineiro - listas nominais de habitantes 
Em distritos como Caeté, o nível de atendimento à população em idade escolar era bastante elevado, ficando muito próximo de $80 \%$. Por outro lado, era baixo em distritos como Matosinhos, que apresentou índices inferiores a 20\%. A média de atendimento à população em idade escolar dos dez distritos ficou em 43,6\% e esse percentual pode ser considerado baixo, pois não podemos deixar de levar em conta que utilizamos como referência a lei que determinou a exclusão do sexo feminino e dos escravos, definindo como público apropriado à escolaização apenas os meninos livres de 8 a 14 anos.

A instrução do sexo feminino era uma tendência que se manifestava com força no século XIX, prova disso é a sua presença na lei de 1835, que não a definiu como obrigatória, mas estabeleceu dispositivos que incentivavam a instrução das meninas:

Art. 3․ O Governo poderá estabelecer também Escolas para meninas nos lugares em que as houver do 2o. grau e em que, atenta a população, puderem ser habitualmente freqüentadas por vinte e quatro alunas ao menos. Nestas Escolas se ensinarão, além das matérias do 1o. grau, ortografia, prosódia, noções gerais dos deveres morais, religiosos e domésticos. (LIVRO DAS LEIS MINEIRAS, pg. 30)

Portanto, considerando essas recomendações estabelecidas pela lei, ampliamos a população em idade escolar e incorporamos a ela as crianças do sexo feminino, na mesma faixa etária do masculino, ou seja, 8 a 14 anos, para, com base nas listas nominais, projetar, de forma mais realista, a população em idade escolar no início da década de 1830.

Gráfico 5: População em idade escolar, incluindo os dois sexos - (\%)

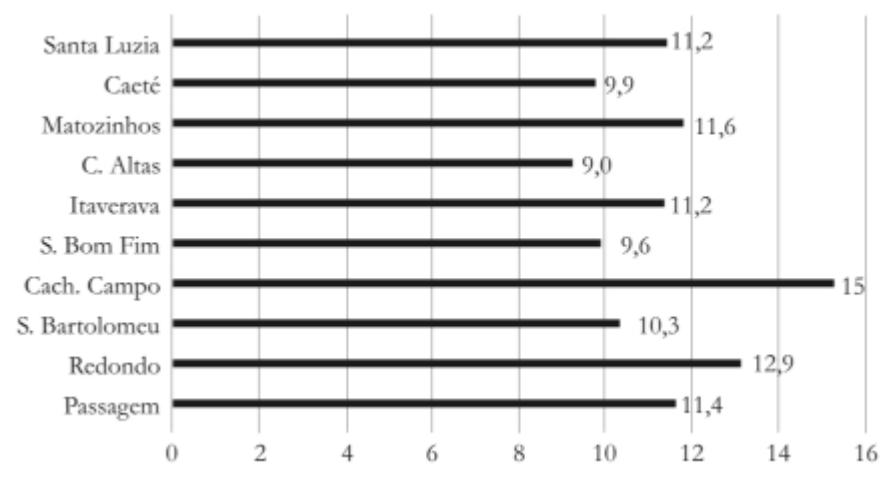

Fonte: Arquivo Público Mineiro - lista nominal de habitantes 
Quando consideramos os dois sexos, a população em idade escolar aumenta consideravelmente e atinge níveis que são quase o dobro daquele que foi calculado quando consideramos apenas o sexo masculino. A média em relação à população total aumenta de $6,1 \%$ para $11,2 \%$. Consequentemente, há alteração significativa na média de atendimento da população em idade escolar, como pode ser visto no gráfico:

Gráfico 6: Nível de atendimento da população em idade escolar, incluindo os dois sexos (\%)

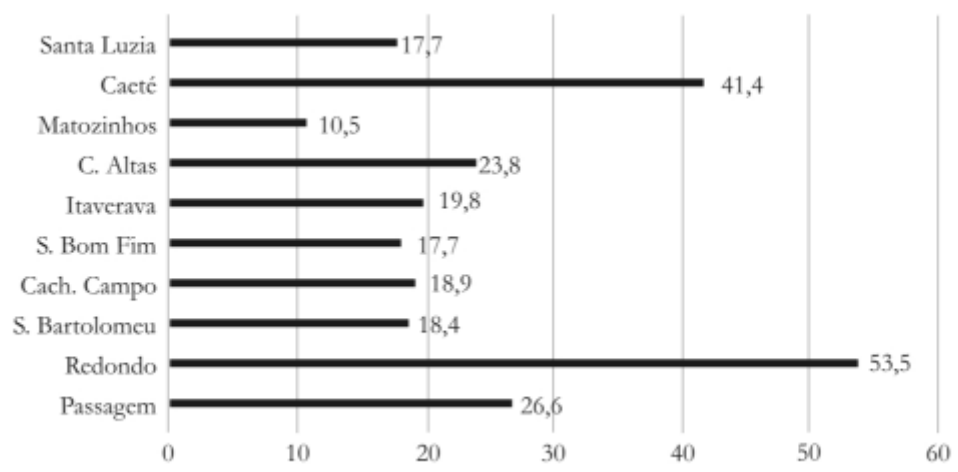

Fonte: Arquivo Público Mineiro - lista nominal de habitantes

Ocorre mudança significativa no padrão de atendimento quando consideramos o sexo feminino na população em idade escolar, pois a média de atendimento atingiu 43,6\%, quando foi considerado apenas o sexo masculino, e caiu para $24,8 \%$, quando levamos em conta os dois sexos.

Essa queda se justifica pelo aumento total da população em idade escolar e também porque a presença de meninas nas escolas era muito pequena. A partir de 1835, houve certa expansão do registro de aulas para meninas, mas, em relação ao período das listas nominais, 1831, o número de mulheres registradas como na escola era praticamente insignificante: nas dez listas, encontramos apenas 39 meninas registradas. Se considerarmos que um dos critérios que utilizamos para seleção das listas nominais foi o fato de registrarem o número mínimo de 24 indivíduos na escola, fica evidente a desproporção entre a presença dos dois sexos em espaços escolares. Essa acentuada vantagem em relação ao sexo masculino justifica o fato de haver grande queda no atendimento da população em idade escolar, quando contabilizamos os dois sexos. 
Essa estimativa que construímos para os dois sexos não nos permite projetar de fato a população em idade escolar como viria a ser definida nos períodos posteriores, pois nela não estão presentes as crianças que foram registradas como escravas.

Uma das principais características da sociedade mineira era o fato de que nela havia grande número de escravos, e essa população escrava se distinguia por apresentar comportamento singular em relação ao seu processo de recomposição:

Comprovações documentais bastante evidentes demonstram que o impressionante aumento demográfico dos escravos de Minas durante o século 19 resultou em grande parte da reprodução natural, e não da importação da África por meio do comércio escravagista. Não existe nenhum outro exemplo conhecido de qualquer sociedade escravagista de grande porte na América e no Caribe em que isto tenha ocorrido, e há muitíssima probabilidade de que este seja um exemplo único na história da escravidão no Brasil. (BERGAD, 2004, p. 21)

A historiografia tem destacado como fenômeno singular do escravismo em Minas a capacidade de recomposição do plantel de escravos a partir da reprodução no interior do próprio cativeiro. Isso quer dizer que, em Minas, não era incomum encontrar crianças que haviam nascido como escravas. Como consequência desse comportamento, temos número significativo de crianças escravas que se encontravam na faixa etária dos 8 a 14 anos, ou seja, o grupo de idade estabelecido como escolar.

O que foi definido como idade escolar pela Lei n. 13 é algo que só tem sentido nos anos iniciais do Império, pois, nos períodos posteriores, essa noção se alargaria, incorporando o sexo feminino e a população que tinha sua origem no cativeiro. Portanto, se quisermos construir uma visão mais condizente da população em idade escolar e que se aproxime do padrão de cálculo que passou a balizar os períodos posteriores, é necessário acrescentar as crianças escravas ao segmento que compõe a população em idade escolar. 
Gráfico 7: População em idade escolar, incluindo escravos - (\%)

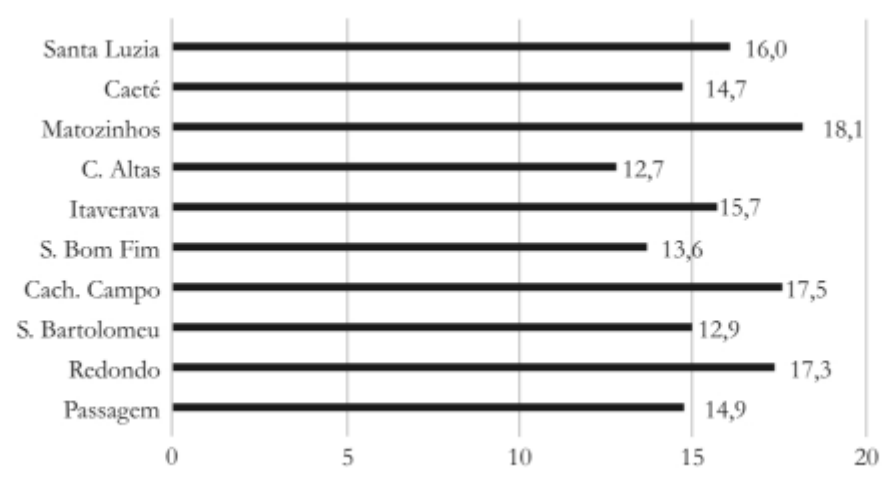

Fonte: Arquivo Público Mineiro - lista nominal de habitantes

Quando acrescentamos as crianças escravizadas à população em idade escolar, há aumento desse grupo, que, em média, passa a representar $15,3 \%$ da população total. Como os escravos em idade escolar estavam, quase na sua totalidade, fora das escolas - encontramos nas dez listas apenas um escravo registrado como na escola -, o nível médio de atendimento à população em idade escolar sofreu redução, como pode ser visto no gráfico:

Gráfico 8: Nível de atendimento à população em idade escolar, incluindo escravos (\%)

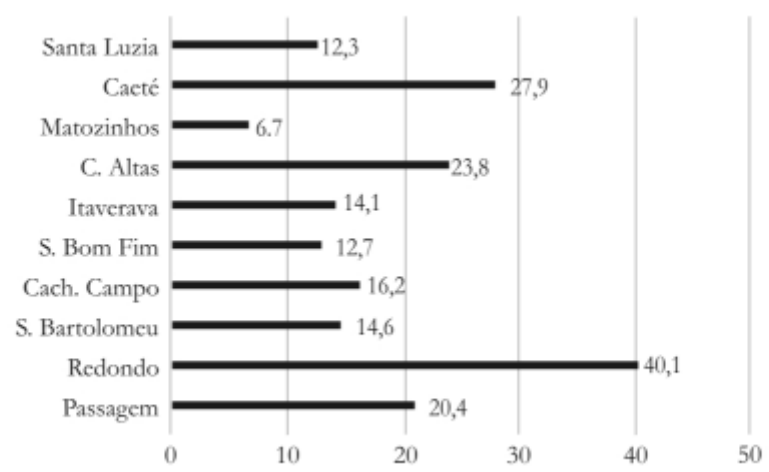

Fonte: Arquivo Público Mineiro - listas nominais de habitantes.

A média de atendimento à população em idade escolar atinge o índice de 18,8\% quando incluímos os escravos. De forma semelhante ao 
que ocorreu em relação ao sexo feminino, temos o aumento dos indivíduos em idade escolar e este não é acompanhado pelo aumento de crianças na escola, ou seja, isso faz com que o índice médio de atendimento fique muito distante dos $43,6 \%$, quando foi considerado apenas o sexo masculino, e relativamente distante dos $24,8 \%$, quando foram considerados os dois sexos.

Portanto, quando ampliamos o conceito de população em idade escolar, a partir da incorporação de categorias como gênero e condição social (escravos), fica evidente que, em termos absolutos, o atendimento à população escolarizável como um todo era muito baixo. ${ }^{3}$ Mesmo se consideramos as restrições estabelecidas pela Lei n. 13, o índice de atendimento ao grupo definido como idade escolar pode ser considerado baixo, pois atingiu apenas 43,6\% dos meninos de 8 a 14 anos dos dez distritos.

Não é possível dimensionar esses dados em relação a toda a província de Minas Gerais, pois são dez distritos para um total de mais de 400 que existiam na região e que possuíam distribuição desigual da população e de escolas, o que torna difícil definir o nível de representatividade dessa amostra. No entanto, os dados relativos a esses dez distritos, que estavam em uma das regiões mais desenvolvidas de Minas, podem ser tomados como indícios do baixo nível de difusão da instrução na população e a distância em relação ao cumprimento da obrigatoriedade escolar, nos termos definidos pela Lei n. 13.

Quando acrescentamos os dados relativos ao atendimento à população em idade escolar àqueles que extraímos dos relatórios de Presidente de Província, e que revelaram ausência de crescimento para as matrículas da instrução elementar entre os anos de 1830 e 1840, fica ainda mais evidente a ideia da obrigatoriedade escolar como algo que buscava demarcar a educação como um símbolo para a formação de um povo civilizado. As listas nominais revelam que era muito baixo o padrão de cobertura da escolarização em 1831 e, como vimos anteriormente, os relatórios de Presidente de Província indicam que esse panorama não mudou após 1835 .

O valor simbólico da obrigatoriedade escolar e dos discursos em relação à instrução vem sendo constantemente reafirmado pela historiografia sobre Minas Gerais. Para Gouvêa (2004, p. 190): 
A promulgação da lei da obrigatoriedade escolar buscava instaurar uma nova realidade: a escolarização da infância, ou, mais exatamente, da meninice, imputando aos pais a responsabilidade legal por sua efetivação. Escolarização essa focada no universo populacional masculino. Em que pese o fato de que lei parece não ter sido de fato efetivada ela inaugurou no âmbito do Estado um discurso que estabelece a escola como espaço formativo da infância ou melhor, da meninice (ou idade da razão) período de vida concebido como favorável a tais aprendizados.

Para Gouvêa (2004), o caráter simbólico da obrigatoriedade manifestava-se na demarcação da escola como espaço efetivo de formação da infância, representando uma tentativa de intervenção no poder e na responsabilidade das famílias de ministrar a educação ou determinar os espaços sociais onde a infância deveria ser vivenciada.

$\mathrm{Na}$ mesma perspectiva segue a interpretação de Faria Filho e Gonçalves (2004, p. 161), que acentuam a ligação da lei com a infância a partir das penalidades estabelecidas e da faixa etária definida como escolarizável:

Cumpre chamar atenção, além da possibilidade de imposição de multas, para a determinação legal da idade escolar entre 8 e 14 anos. Tal aspecto revestese de uma importância simbólica expressiva, uma vez que traduz, de certa forma, o pensamento dos legisladores acerca da infância e da sua educabilidade, num momento em que a escola era freqüentada por pessoas de idades bastante diferenciadas.

O sentido político da obrigatoriedade escolar foi ressaltado por Veiga (2006, p. 5), que entende esse ato como uma iniciativa importante para a produção de um sentimento de pertencimento à nação:

A institucionalização da obrigatoriedade dos pais ou responsáveis em dar a instrução elementar às crianças foi um acontecimento predominantemente político. Compunha o conjunto de normatizações necessárias à produção da consciência de um pertencimento nacional, onde perpassa um imaginário de sociedade cujos membros deveriam compartilhar obrigações e direitos. A escola se apresenta como uma unidade de referência civilizatória, produtora de novos valores e atitudes. Os diferentes saberes em profusão no século XIX sistematizaram uma condição de criança e de ter infância e para isso diferentes códigos identificadores foram produzidos para a criança: obediente, comportada, freqüentar escolas, ser bom filho e bom aluno. 
A contraposição entre a realidade educacional de Minas e a lei que determinou a obrigatoriedade da instrução elementar tem levado os historiadores a ressaltar sua dimensão simbólica na demarcação da ação estatal em relação às questões ligadas à infância e à formação de uma sociedade com feições modernas. Essas interpretações são coerentes e estão em sintonia com o processo de estabelecimento da escolarização enquanto elemento constitutivo da modernidade. Porém, não dizem tudo sobre o estabelecimento desse acontecimento, que pode adquirir outros significados quando considerado a partir do elemento que mais diretamente singularizava a sociedade mineira, ou seja, o perfil racial de sua população.

\section{O PERFIL RACIAL DA POPULACְÃO MINEIRA COMO COMPONENTE DE UM DISCURSO CIVILIZATÓRIO}

A obrigatoriedade da instrução elementar como componente simbólico de um projeto civilizacional adquire um sentido específico quando associamos esse processo a aspectos populacionais, entre eles aquele que mais diretamente caracterizava as Minas Gerais e estava relacionado com o predomínio absoluto da população negra em sua estrutura demográfica. Clotilde Paiva (1996) utilizou os dados censitários referentes à década de 1830 para estabelecer uma estimativa da população livre de Minas e registrou o número de 269.916 indivíduos nessa condição. Segundo a autora, a população livre tinha a seguinte composição racial:

Gráfico 9: Distribuição da população livre de Minas Gerais - por raça-cor (1831-1838)

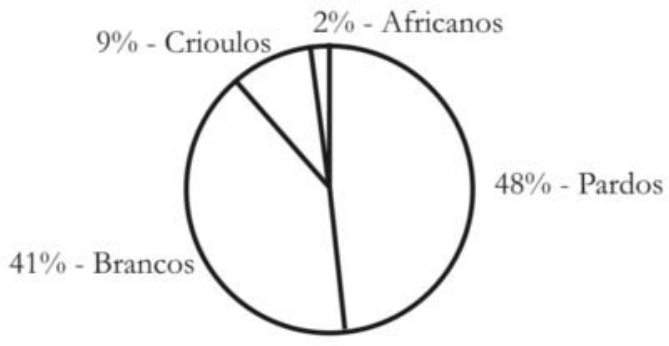

Fonte: adaptado de Clotilde Paiva. Populacão e economia nas Minas Gerais do século XIX. Sấo Paulo: Tese de Doutorado, FFLCH/USP, 1996. 
Os negros (pardos, crioulos, africanos) representavam a maioria da população livre da província, com um total de 59\% dos habitantes. Quando acrescentamos a essa população os dados que a pesquisadora apresenta sobre o plantel de escravos, 127.366 indivíduos - quase metade da população livre -, não resta dúvida quanto à presença hegemônica dos negros na população mineira.

Essa supremacia pode ser constatada pela população dos distritos que tomamos para análise. Isso fica claro quando subdividimos a população nas categorias de brancos, escravos e negros livres, que são distinções que podem ser tomadas como revestidas de amplo significado no universo social do século XIX:

Gráfico 10: Brancos, escravos e negros livres registrados nas listas nominais
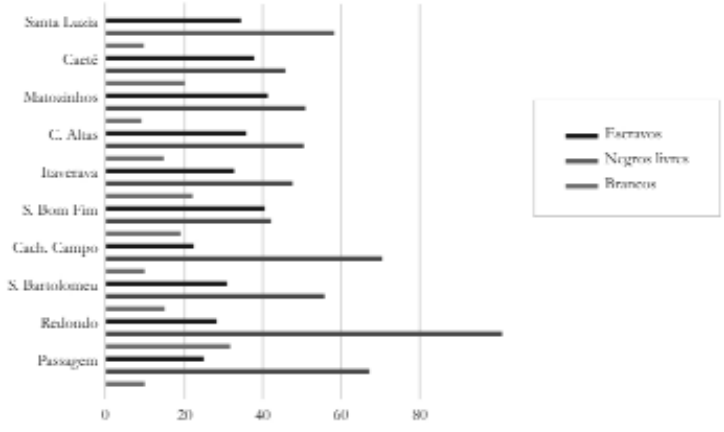

Fonte: Arquivo Público Mineiro - listas nominais de habitantes

Os dados relativos à população dos dez distritos que analisamos reafirmam o que foi indicado por Paiva (1996). Isso pode ser atestado quando agregamos os negros livres e os escravos, contrapondo-os à população branca. Há enorme discrepância entre esses dois grupos, sendo que os brancos não chegavam a compor sequer um terço da população de nenhum dos distritos que analisamos. Apenas em Redondo a população branca estava próxima de 30\%, nos demais, ela estava, em geral, abaixo de um quinto da população total ${ }^{4}$.

$\mathrm{Na}$ visão das elites do século XIX, essa composição da população era tida como negativa e determinava a necessidade da construção de instrumentos de controle social para moralizar e civilizar o povo.

No período mais próximo à abolição da escravidão, entre 1850 e 1888, o predomínio dos negros na população brasileira passou a ser 
duramente criticado e as propostas de superação dessa marca racial foram concebidas como estratégias de combate àquilo que era chamado de processo de africanização do país.

No período que tomamos para análise (1830-1840), em que vigorava plenamente a escravidão e no qual praticamente não havia restrições ao trabalho escravo ${ }^{5}$, as críticas ao perfil racial da população não eram diretas, pois criticar a africanização do país implicaria colocar em questão a escravidão como instituição responsável pela introdução dos negros escravizados na sociedade brasileira. Nesse sentido, o tráfico de escravos e os negros eram concebidos como elementos que desempenhavam papel estratégico na vida do país. Isso pode ser visto no parecer da Comissão de Diplomacia e Estatística sobre o acordo entre Brasil e Inglaterra para abolição do tráfico de africanos em 1827:

É prematura (a abolição do tráfico) por não termos por ora no Império do Brasil uma massa de população tão forte, que nos induza a rejeitar um imenso recrutamento de gente preta, que pelo decurso do tempo, e pela mistura de outras castas, chegaria ao estado de nos dar cidadãos ativos e intrépidos defensores da nossa pátria. É extemporânea, por ser ajustada em uma época em que a Câmara dos Deputados havia apresentado um projeto para diminuir gradualmente a importação da escravatura para o Brasil; e por não nos pertencerem mais as Ilhas dos Açores, de onde nos podia vir um imenso número de colonos infatigáveis, que povoassem a beira-mar, e os sertões do nosso Império. (Apud: LIMA, 2003, p. 96)

Os elementos acionados pelo discurso da Comissão na tentativa de evitar a abolição do tráfico de africanos, em 1827, eram falaciosos, pois é evidente que o recrutamento de gente preta não estava relacionado à construção de um povo que fosse capaz de defender a pátria, como quer fazer crer o Parecer. $\mathrm{Na}$ verdade, tratava-se de defender o tráfico de africanos como elemento fundamental para a manutenção da escravidão. Dessa forma, o parecer indica a importância dessa população e a impossibilidade que existia, naquele período, de se empreender uma crítica à africanização do país, como ocorreu com intensidade após os anos de 1850, quando, de fato, foi estabelecido o fim do tráfico de africanos, indício claro de que a escravidão encaminhava-se para o fim.

No contexto dos anos de 1820, o reconhecimento da importância dos africanos estava restrito à sua função de trabalhadores escravizados, pois tudo o que estava ligado a esse grupo e transcendia o mundo 
do trabalho era objeto de crítica. Isso pode ser constatado nas considerações sobre as influências negativas que os escravos difundiam na sociedade brasileira, o que era tomado como algo que deveria ser combatido. Um dos instrumentos reconhecidos como necessários para esse combate era a educação, que deveria ser utilizada como forma de minimizar os problemas decorrentes de uma sociedade na qual os escravos se faziam presentes tanto no mundo público quanto no privado. É o que revela o Presidente da Província Bernardo Jacintho da Veiga (1840, p. 37), em sua Fala Dirigida à Assembléia Provincial de Minas:

Outra causa não menos poderosa, a meu ver, que também embarga o rápido desenvolvimento da instrução em diversas Escolas, consiste na educação viciosa de algumas casas de famílias, ou pela triste necessidade de confiarem seus filhos ao cuidado de escravos, que jamais poderão inspirar-lhes sentimentos generosos. Se um hábil professor pudesse encarregar-se da educação de um menino desde o berço, seu trabalho seria seguramente coroado do mais feliz sucesso, mas os que entram para a escola tem já recebido certos princípios, que quando maus, não se podem corrigir com facilidade.

Na crítica apresentada pelo Presidente da Província, a escravidão não é condenada e nem tampouco apresentada como problema. O que de fato incomodava eram as influências difundidas pelos escravos, e isso tornava necessária a difusão da instrução, que era idealizada como algo que deveria ocorrer a partir da ação de um hábil professor, que, como o preceptor do Emílio, de Rousseau, deveria educar a criança desde o berço.

A questão, que foi colocada em destaque pelo Presidente da Província, aparece também no relato do viajante alemão Eschwege (1996, p. 80). ${ }^{6}$ Para ele, um frágil contato das crianças com a educação não seria capaz de sobrepor as influências adquiridas na convivência com escravos no mundo privado: "as crianças de ambos os sexos são entregues aos cuidados de escravas que não coíbem seus vícios nem mesmo na presença das suas pupilas. Estas, logo acostumadas, tratam de seguir-lhes o exemplo".

A ação educativa dos escravos e a forma negativa como esta era avaliada também pode ser registrada no testemunho de Francisco de Paula Ferreira Rezende, que escreveu um livro chamado Minhas Recordações, no qual, entre outras coisas, registra sua infância na Vila de Campanha, nos anos de 1830 e 1840. Uma das coisas que Rezende (1944, p. 108) destaca 
é a influência que sobre ele exerceu uma escrava chamada Margarida, com a qual conviveu durante toda a infância:

Nem se estranhe que assim me ocupe, e com uma tão grande e quase excessiva minuciosidade de uma simples preta escrava; porque se aqui não omito os meus parentes mais ou menos nobres e se de preferência procuro falar de gente e de coisas grandes, contudo o que principalmente me dirige a pena, é a lembrança daqueles a quem mais devo ou que mais me amaram neste mundo; e esta pobre e alegre negra tanto me amou, tantas vezes me teve ao colo, que ainda mesmo que eu quisesse, não poderia jamais dela me esquecer. Outra circunstância, porém, existe ainda, que faz com que eu não pudesse deixar de mencioná-la aqui; é, que um dos pontos do meu programa é o deixar registrado escrito o nome de todos os meus mestres; e ainda que nunca professasse de cadeira, a Margarida sabia tanta coisa e tanta coisa me ensinou, que ela não pode deixar de entrar na classe dos meus bons professores.

Como haviam apontado o Presidente de Província e o viajante europeu, a presença de escravos no mundo privado e o fato de assumirem a responsabilidade de criar os filhos de seus senhores possibilitavam a transmissão de uma série de conhecimentos que estavam ligados a uma cultura que era vista como ameaçadora. O depoimento de Francisco de Paula Ferreira Rezende deixa claro que a relação entre as crianças e os escravos se dava em um nível de intensidade que, mesmo sem professar cadeira, a escrava Margarida não podia deixar de ser contabilizada como uma de suas mestras.

A utilização de termos escolares na qualificação da relação que estabeleceu com a escrava indica o nível de influência que teve a cativa Margarida no aprendizado recebido pelo menino Francisco de Paula Ferreira Rezende. Mas a transposição dos termos escolares para o contexto de sua relação com a escrava também indica que ele estabeleceu contatos com processos de educação formal em nível suficiente para adquirir outros mestres e outros conteúdos, que lhe permitiram reavaliar o aprendizado que recebeu dessa estranha mestra. Francisco de Paula Ferreira Rezende (1944 p. 108) qualifica negativamente as influências que os escravos lhe transmitiram durante a infância: "com isso não quero dizer, que uma tal aprendizagem e que sendo sobretudo feita em uma idade tão tenra como era a minha, não deixasse de ter os seus inconvenientes; pois que, além de ser isso uma dessas coisas que a razão 
nos mostra, eu ainda sei, e o sei muito bem, que para mim os teve, com efeito, e de uma natureza quase irremediável".

A experiência como branco de família relativamente abastada obrigou Francisco de Paula Ferreira Resende a tentar superar o misticismo e as superstições que absorveu no contato com os escravos. Essa experiência se aproxima muito da crítica que, em 1840, fez o Presidente da Província e indica que a relação entre educação e civilização tinha na escravidão um elemento de mediação e isso demarcava a necessidade de difusão da instrução elementar. ${ }^{7}$

Nesse sentido, a obrigatoriedade da difusão da instrução pode estar relacionada com o perfil racial da população mineira que, em maiores proporções que em outras províncias, tinha a necessidade de colocar em circulação os elementos considerados necessários à civilização do povo. A recorrência com que se insistia na vinculação entre educação e civilização pode estar revestida desses elementos que caracterizaram a sociedade mineira na primeira metade do século XIX. Segundo Veiga (2003, p. 42):

Neste sentido, o discurso da educação, fator universalmente constituído na modernidade como possibilidade de uma homogeneidade cultural, prérequisito para o progresso, possuiu no Brasil uma singularidade em relação a outros países, ou seja, foi tomado em negativo. Ao afirmar as associações entre educação e civilização, as elites indicavam para a existência de uma barbárie que não estava na Igreja, ou ainda apenas nas supertições, nos gestos e nos hábitos da população, mas antes na sua cor de pele, na sua origem étnico-racial.

Nesse sentido, a obrigatoriedade da instrução e o caráter civilizacional que marcou os discursos da educação podem adquirir um significado específico quando os contrapomos às características da população mineira e sua relação com a escravidão. A partir desse contraponto, o caráter simbólico do discurso sobre a obrigatoriedade escolar pode ser associado ao perfil racial da população mineira que foi profundamente marcado pelas práticas escravistas, fazendo com que os africanos e seus descendentes predominassem na estrutura demográfica.

Esse fato pode ser tomado como uma das justificativas para que a legislação mineira fosse além do que havia sido definido pela Constituição do Império, tornando-se uma das primeiras províncias 
brasileiras a instituir a gratuidade e a obrigatoriedade da instrução, estabelecendo, inclusive, punições para os pais que não enviassem seus filhos às escolas. A educação era concebida como elemento fundamental na constituição de um povo civilizado e esta não era uma das características atribuídas à população negra. Portanto, era exatamente onde predominava essa população que a educação deveria ser tomada como instrumento essencial na constituição de um povo civilizado. Nesse sentido, a ideia de civilização adquire uma dimensão específica e também pode ser considerada como uma metáfora da raça e da necessidade de combater as influências disseminadas pelos negros na sociedade mineira ${ }^{8}$.

Essa hipótese torna-se ainda mais plausível quando constatamos que a população negra não era apenas um dos públicos aos quais a escola estava destinada, mas aquele que efetivamente se fazia presente na instrução elementar. Quando utilizamos as informações das listas nominais para elaborar um perfil racial das escolas, constatamos que, em todos os distritos, os negros eram maioria entre os que foram registrados na condição de alunos das escolas de instrução elementar.

Gráfico 11: Número de indivíduos na escola elementar registrado nas listas nominais - por raça

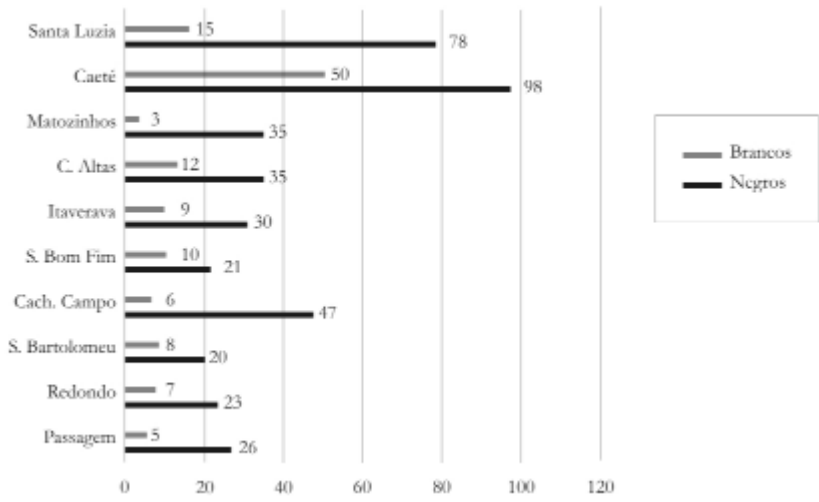

Fonte: Arquivo Público Mineiro - listas nominais de habitantes

Em nenhum dos dez distritos que analisamos os brancos se faziam presentes na escola em número superior aos negros?. Esses dados indicam que havia uma relação entre a população e o perfil da escola, ou seja, os negros eram maioria na população e essa condição se refletia também nas escolas, onde eles eram numericamente superiores aos brancos ${ }^{10}$. 


\section{CONSIDERAÇÕES FINAIS}

No contexto dos anos de 1830, o estabelecimento da obrigatoriedade da instrução elementar não passou de uma intenção. Isso fica evidente quando consideramos o nível de atendimento à população em idade escolar e o baixo crescimento das matrículas nas escolas mineiras das décadas de 1830 e 1840. Dessa forma, a definição da obrigatoriedade escolar pode ser concebida como a representação de um ideário civilizatório que entendia que a educação tinha papel fundamental no processo de controle da população. Nessa perspectiva, a ideia de civilizar o povo pode ser tomada como algo que comporta um nível de articulação entre educação e raça. A ideia de civilização como metáfora de processo racializado pode ser um indício dos antecedentes históricos da relação entre a questão racial e a educação brasileira, pois este seria, desde o século XIX, elemento constitutivo de sua identidade como prática social.

Talvez isso possa explicar as dificuldades que, na atualidade, a área educação vem enfrentando para redimensionar suas formas de tratamento em relação à população negra. Ou seja, o que está em questão no debate contemporâneo não é apenas um conjunto de práticas pedagógicas difusas que tendem a desqualificar a população negra, mas um projeto civilizatório que procurou se estabelecer por meio da educação e que remonta ao próprio processo de constituição do Brasil como nação.

\section{DOCUMENTOS CONSULTADOS}

- Lista nominal dos habitantes de Bom Fim. Arquivo Público Mineiro: Fundo Presidente de Província - Documentos Microfilmados - rolo 02, caixa 06, doc 15.

- Lista nominal dos habitantes de Cachoeira do Campo. Arquivo Público Mineiro: Inventário Sumário dos Mapas de População - Documentos Microfilmados - rolo 01, caixa 01 , pacotilha 09 .

- Lista nominal dos habitantes de Catas Altas. Arquivo Público Mineiro: Inventário Sumário dos Mapas de População - Documentos Microfilmados - rolo 07, caixa 18, doc 09 .

- Lista nominal dos habitantes de Itaverava. Arquivo Público Mineiro: Inventário Sumário dos Mapas de População - Documentos Microfilmados - rolo 02, caixa 04, pacotilha 21.

- Lista nominal dos habitantes de Matosinhos. Arquivo Público Mineiro: Inventário Sumário dos Mapas de População - Documentos Microfilmados - rolo 06, Caixa 11, pacotilha 07 . 
- Lista nominal dos habitantes de São Bartolomeu. Arquivo Público Mineiro: Inventário Sumário dos Mapas de População - Documentos Microfilmados - rolo 01, Caixa 01, pacotilha 01 .

- Lista nominal dos habitantes de Passagem de Mariana. Arquivo Público Mineiro: Inventário Sumário dos Mapas de População - Documentos Microfilmados - rolo 07, caixa 17 , doc. 05

- Lista nominal dos habitantes de Redondo. Arquivo Público Mineiro: Inventário Sumário dos Mapas de População - Documentos Microfilmados - rolo 02, caixa 03, pacotilha 26.

- Lista nominal dos habitantes de Santa Luzia. Arquivo Público Mineiro: Fundo Presidente de Província - Documentos Microfilmados - rolo 13, caixa 35, doc 04.

- Lista nominal dos habitantes de São Gonçalo. Arquivo Público Mineiro: Inventário Sumário dos Mapas de População - Documentos Microfilmados - rolo 02, Caixa 02, pacotilha 18 .

ESCHWEGE, Wilhelm Ludwig Von. Brasil, novo mundo. Belo Horizonte: Centro de Estudos Históricos e Culturais, Fundação João Pinheiro, 1996.

LIVRO DAS LEIS MINEIRAS. Ouro Preto (1835 - 1883). Arquivo Público Mineiro.

REZENDE, Francisco de Paula Ferreira. Minhas recordações. Rio de Janeiro: Livraria José Olympio Editora, 1944. (Coleção Documentos Brasileiros, volume 45)

Relatórios de Presidente de Província de Minas Gerais de 1837 a 1851. Disponível em: $<$ http://www.crl.edu/content.asp $>$.

\section{REFERÊNCIAS}

BERGAD, Laird W. Escravidão e história econômica: demografia de Minas Gerais (17201880). Bauru/São Paulo: EDUSC, 2004.

ELIAS, Norbert. Escritos e Ensaios: Estado, processo, opinião pública. Rio de Janeiro: Jorge Zahar, 2006.

FARIA FILHO, Luciano Mendes; GONÇALVES, Irlen. Processo de escolarização e obrigatoriedade escolar: o caso de Minas Gerais (1835-1911). In: FARIA, FILHO, Luciano Mendes (Org.). A infância e sua educação: materiais, práticas e representações (Portugal e Brasil). BH: Autêntica, 2004.

FARIA FILHO, Luciano Mendes; RESENDE, Fernanda Mendes. A história da política educacional em Minas Gerais no século XIX: os relatórios dos presidentes de província. Revista Brasileira de História da Educação, 2001.

FONSECA, Marcus V. A arte de construir o invisível: o negro na historiografia educacional brasileira. Revista Brasileira de História da Educação. São Paulo: Sociedade Brasileira de História da Educação, n. 13, 2007.

FONSECA, Marcus V. A educação dos negros: uma nova face do processo de abolição do trabalho escravo no Brasil. Bragança Paulista: Ed da Universidade São Francisco, 2002. FONSECA, Marcus V. Pretos, pardos, crioulos e cabras nas escolas mineiras do século XIX. Faculdade de Educação (Tese). Doutorado em Educação, USP, 2007.

GOUVEA, Maria Cristina Soares de. Meninas nas salas de aula: dilemas da escolarização feminina no século XIX. In: FARIA FILHO, Luciano Mendes (Org.) A infância e sua educação: materiais, práticas e representações (Brasil e Portugal). Belo Horizonte: Autêntica, 2004. 
GOUVEA, Maria Cristina Soares de. A escolarização da "meninice" nas Minas oitocentista: a individualização do aluno. In: FONSECA, Thais Nívia de Lima; VEIGA, Cynthia Greive. História e historiografia da educação no Brasil. Belo Horizonte: Autêntica, 2003.

LIMA, Ivana Stolze. Cores, marcas e falas: sentidos da mestiçagem no Império do Brasil. Rio de Janeiro: Arquivo Nacional, 2003.

MARTINS, Ângela Magalhães. Século XIX: estrutura ocupacional de São João Del Rei e Campanha. In: $V$ Seminário sobre economia mineira. BH: Centro econômico de desenvolvimento e planejamento regional da Faculdade de Ciências Econômicas da UFMG, 1990.

MENEZES, Jacy Maria Ferraz de. Igualdade y libertad pluralismo y cidadania: el acesso a la educacion de los negros y mestizos em Bahia. Universidade Católica de Córdoba (Tese de doutorado), Cordoba/Argentina, 1997.

PAIVA, Clotilde A. População e economia nas Minas Gerais do século XIX. FFLCH/USP, São Paulo, (Tese de Doutorado), 1996.

SALES, Zeli Efigenia Santos de. O Conselho Geral da Província e a política de instrução pública em Minas Gerais (1825-1835). Faculdade de Educação, Dissertação de Mestrado, UFMG, 2005. VEIGA, Cynthia Greive. Crianças negras e Mestiças no processo de institucionalização da instrução elementar, Minas Gerais, século XIX. In: Congresso brasileiro de história da educação, 3, Anais. Curitiba: Sociedade Brasileira de História da Educação, 2004.

VEIGA, Cynthia Greive. Cultura escrita e educaşão: representações de criança e imaginário de infância, Brasil, século XIX. Belo Horizonte, 2006. (mimeo.)

VEIGA, Cynthia Greive. História política e história da educação. In: FONSECA, Thais Nívia de Lima; VEIGA, Cynthia Greive (Orgs.). História e historiografia da educação no Brasil. Belo Horizonte: Autêntica, 2003.

\section{NOTAS}

${ }^{1}$ Tendo como referência o fato de que a lei estabeleceu obrigatoriedade escolar apenas para o sexo masculino, não consideramos as alunas matriculadas, mas o número delas era praticamente insignificante e, quando considerado, não altera o desenho da curva que apresentamos no Gráfico 1.

${ }^{2}$ Este colégio tinha perfil muito semelhante ao colégio do Caraça, sendo inclusive administrado pelos padres da mesma congregação.

${ }^{3}$ Estes dados se aproximam daquilo que foi estabelecido pelo censo de 1872 em relação à população analfabeta com idade superior a 5 anos, de todo o país. Segundo dados apresentados por Rui Barbosa, os analfabetos representavam 85,5\% da população brasileira. Ver Menezes (1997).

${ }^{4}$ Este índice de brancos no distrito de Redondo também ocorria em função do registro do Colégio Bom Jesus de Matozinhos como domicílio, pois, como já dissemos, isso exercia influência no perfil da população. Havia predomínio absoluto dos brancos como estudantes e professores nessa instituição e a reunião desses indivíduos representava algo superior a $10 \%$ da população, o que, por sua vez, elevava o contingente de brancos no perfil demográfico do distrito. 
${ }^{5}$ Entre as mais importantes restrições ao trabalho escravo está o fim do tráfico de africanos, que foi estabelecido desde de a década de 1820, mas efetivado apenas em 1850, e a libertação das crianças nascidas de mulheres escravas, em 1871. Foram essas as medidas que estavam no cerne daquilo que a historiografia denominou processo de abolição do trabalho escravo. Há outras de menor impacto, mas importantes dentro do contexto da abolição, entre elas destaca-se o favorecimento do pecúlio por parte dos escravos, a proibição da venda de famílias de escravos em separado, o fim do cativeiro para as pessoas idosas e o fim da escravidão em algumas províncias do Império. Para uma análise desse assunto e suas relações com a educação, ver Fonseca, Marcus V. $A$ educação dos negros: uma nova face do processo de abolição do trabalho escravo no Brasil. Bragança Paulista-SP, Ed. Universidade de São Francisco, 2002.

${ }^{6}$ O alemão Wilhelm Ludwig Von Eschwege (1777-1855) esteve no Brasil entre 1810 a 1821, vivendo praticamente todo este período em Minas Gerais, onde trabalhou desenvolvendo atividades ligadas à mineralogia. Suas impressões sobre as Minas Gerais e o Brasil foram publicadas pela primeira vez em 1824, na Alemanha, em um livro cujo título era Brasil, novo mundo.

${ }^{7}$ Em 1867, o escritor e professor carioca Joaquim Manoel de Macedo escreveu um livro chamado Vitimas-algozes: quadros da escravidão, cujo conteúdo era uma crítica à ação educativa dos escravos no mundo privado. Para uma análise desse livro e desse tema no contexto do processo de abolição do trabalho escravo, ver Fonseca (2002).

${ }^{8}$ A ideia de civilizar tem em Norbert Elias (2006) um de seus principais intérpretes: “embora os seres humanos não sejam civilizados por natureza, possuem por natureza uma disposição que torna possível, sob determinadas condições, uma civilização, portanto uma auto-regulação individual de impulsos do comportamento momentâneo, condicionado por afetos e pulsões, ou desvio desses impulsos de seus fins primários para fins secundários, e eventualmente também sua reconfiguração sublimada... portanto, de formas específicas de auto-regulação, que eles absorvem mediante o aprendizado de uma linguagem comum e nas quais, então, se encontram: no caráter comum do habitus social, da sensibilidade e do comportamento dos membros de uma tribo ou de um Estado nacional. $\mathrm{O}$ conceito de caráter nacional refere-se a isso. Ele pode ter valia como instrumento de pesquisa no âmbito da teoria da civilização (grifo do autor)" (ELIAS, 2006, p. 21-23).

${ }^{9}$ Em relação ao distrito de Redondo, desconsideramos os dados relativos ao domicilio representado pelo Colégio Bom Jesus do Matosinhos, que, assim como o Colégio Caraça, possuía um perfil altamente elitizado e era exceção em relação às escolas mineiras. Ver Fonseca, M. Pretos, pardos, crioulos e cabras nas escolas mineiras do século XIX. São Paulo: Tese de Doutorado FE-USP, 2007.

${ }^{10}$ Quando comparamos os dados da listas nominais a um conjunto de listas de alunos que, nos anos de 1820 e 1830, foram enviadas por professores ao Governo da Província em cumprimento a uma determinação que, entre outras coisas, os obrigava a registrar a frequência de seus alunos, constatamos que o predomínio numérico dos negros se dava tanto em aulas públicas quanto particulares. 
Recebido: $07 / 08 / 2008$

Aprovado: 12/12/2008

Contato:

Grupo de Estudos e Pesquisa em História da Educação (GEPHE) Faculdade de Educação - UFMG - Campus UFMG Av. Antônio Carlos, 6627 - Sala 1564

Belo Horizonte - MG CEP 31270-901 